\title{
Alcohol, policy, and public health in Lithuania: what was done and what might the effects be?
}

\author{
Mindaugas Štelemèkas \\ Lithuanian University of Health Sciences, Medical Academy, Faculty of Public Health, Health Research Institute, Lithuania
}

\begin{abstract}
ADDRESS FOR CORRESPONDENCE: Mindaugas Štelemèkas, PhD, Public Health Research Centre Lithuanian University of Health Sciences (LSMU), Tilžès g. 18, LT-47181 Kaunas, Lithuania, e-mail: mindaugas.stelemekas@Ismuni.lt
\end{abstract}

Supplementary materials (slides) are available in Webappendix 13 at the journal's website: https://www.termedia.pl/Journal/Journal_of_ Health_Inequalities-100.

Introduction: During the last 20 years Lithuania has undergone some dramatic changes in the field of alcohol control, which have resulted in significantly changed levels of the health burden of alcohol and which have sparked a debate in Lithuanian society about how to improve the situation.

Objective: To review some of the most important milestones in the development of Lithuanian alcohol control policies.

Material and methods: A review of the development of Lithuanian alcohol control policy illustrated with alcohol-related public health indicators derived from national and international open access databases.

Results: Before joining the European Union (EU) in 2004 Lithuania went through a decade-long process of creation of an alcohol control framework (including a dedicated law on alcohol control). However, around the year 2000 alcohol control measures were liberalised (reduction in excise tax, exemption for some low-volume alcohol products, allowance of alcohol sales in petrol stations), which were later boosted by a rapid economic boom (rise in affordability of alcohol) and intense alcohol sales marketing campaigns from the industry. It is likely that these decisions resulted in a rapid deterioration of various alcohol-related indicators as well as a rapid increase in alcohol consumption in the country. In 2007 Lithuania was already among the European Region countries with the highest alcohol consumption levels and highest burden of alcoholrelated harm. The life expectancy declined from 72.2 years in 2000 to 70.8 in 2007 .

In 2008 and 2009 a number of evidence-based ('best buy') policies came into action together with declin- ing affordability of alcohol due to the economic crisis in Lithuania at the end of 2008. Partial restrictions on alcohol advertising were adopted, excise tax of alcohol was increased and tax exemptions were cancelled, drink driving legislation was significantly toughened, and retail alcohol sale at night has been restricted since 2009. The second wave of important alcohol control policies started in 2016 when a ban of alcohol sales in petrol stations came into force. Since March 2017 excise tax for beer and wine has more than doubled and for spirits it has increased by around 23\%. Finally, since 2018 an alcohol advertising ban (with few exceptions) has been in force, sales hours reduced, and the legal purchase age has been increased from 18 to 20 years. These measures may have had an important effect as standardised alcohol-related mortality (mainly alcohol liver disease, poisonings, and cardiomyopathies) rapidly declined (in 2007 there were almost 52 cases per 100,000 while in 2017 there were less than 18 cases per 100,000$)$ and life expectancy increased to almost 76 years in 2017 .

Conclusions: Lithuania has had a mixed experience in the field of alcohol control during the last two decades; however, a recent improvement in alcohol-related public health indicators may be closely associated with the implemented alcohol control policies.

Key words: alcohol, health policy, public health.

\section{DISCLOSURE}

The author reports no conflict of interest. 